\title{
O FENÔMENO ABELHA-RAINHA: QUAIS AS PARTICULARIDADES NA UNIVERSIDADE?
}

Rebeca da Rocha Grangeiro'

D Catherine EsnardII

I Universidade Federal do Cariri, Juazeiro do Norte (CE), Brasil; rebeca.grangeiro@ufca.edu.br

II Universidade de Poitiers, Poitiers, França; catherine.esnard@univ-poitiers.fr

\section{Resumo}

O objetivo desta pesquisa é explorar a ocorrência das características do fenômeno abelha-rainha em uma universidade francesa, observando, em particular, se esse efeito se manifesta de diferentes formas entre docentes-pesquisadores(as) e não docentes de diferentes categorias estatutárias. Vinte e duas entrevistas semidiretivas, realizadas com funcionários e funcionárias, destacam a prevalência de traços característicos da abelha-rainha entre docentes-pesquisadoras de status elevado, muito mais do que entre mulheres não docentes. Os resultados deste estudo exploratório são discutidos no contexto de discriminação baseada em gênero, suscetível de afetar as carreiras das mulheres na universidade.

RELAÇÕES DE GENERO • MULHERES • UNIVERSIDADE • PROFISSÃO

\section{LE PHENOMÈNE REINE DES ABEILLES : QUELLES PARTICULARITES À L'UNIVERSITÉ? Résumé}

Cette recherche a pour objectif d'explorer l'occurrence des caractéristiques de l'effet reine des abeilles dans une université française en observant notamment s'il se manifeste sous des formes différentes entre les enseignant.e.s-chercheu.r.seuse.s et les personnels non enseignants de différentes catégories statutaires. Vingt-deux entretiens semi-directifs individuels, conduits auprès de personnels masculins et féminins, mettent en évidence une prévalence des traits caractéristiques de l'attitude de la reine des abeilles chez les femmes universitaires de statut élevé, bien plus que chez les femmes non enseignantes. Les résultats de cette étude exploratoire sont discutés dans le cadre des discriminations sexistes susceptibles d'impacter les carrières des femmes à l'université.

RELATIONS DE GENRE • FEMMES • UNIVERSITÉ • PROFESSION 


\section{THE QUEEN BEE PHENOMENON: WHAT PECULIARITY AT UNIVERSITY?}

\section{Abstract}

The objective of this research is to explore the occurrence of the queen bee phenomenon characteristics in a French university by observing in particular whether this effect manifests itself in different forms between the professors-researchers and non-professors staff of different statutory categories. Twenty-two individual semi-structured interviews, conducted with male and female personnel, highlight the prevalence of queen bee characteristic traits among high status female professors, much more than among non-professors women. The results of this exploratory study are discussed in the context of gender-based discrimination likely to impact the women careers in university.

GENDER RELATIONS • WOMEN • UNIVERSITY • PROFESSION

\section{EL FENÓMENO ABEJA REINA: ¿CUÁLES SON SUS PARTICULARIDADES EN LA UNIVERSIDAD?}

\section{Resumen}

El objetivo de esta investigación es explorar la ocurrencia de las características del fenómeno abeja reina en una universidad francesa, observando, sobre todo, si ese efecto se manifiesta de distintas formas entre docentes-investigadores(as) y no docentes de diferentes categorías estatutarias. Veintidós entrevistas semiestructuradas individuales realizadas con empleados y empleadas destacan la prevalencia de rasgos característicos de la abeja reina entre docentes-investigadoras de alto status, mucho más que entre mujeres no docentes. Los resultados de este estudio exploratorio se discuten en el marco de la discriminación en base al género, capaz de afectar las carreras de las mujeres en la universidad.

RELACIONES DE GENERO • MUJER • UNIVERSIDAD • PROFESIÓN 


\section{A igualdade de gênero nas universidades francesas: um panorama atenuado}

A igualdade entre mulheres e homens na esfera profissional é atualmente uma questão social considerada importante. Muitas iniciativas foram realizadas nos últimos anos, especialmente na Europa, para permitir a limitação da predominância de homens no mercado de trabalho. A Carta Europeia para Igualdade de Mulheres e Homens na Vida Local (2006) ${ }^{1}$ inclui 30 temas de compromissos, dentre os quais o emprego. Esse documento destaca disposições relativas à implementação de ações positivas, remuneração, promoções, desenvolvimento de carreira, diversidade de empregos e medidas de recrutamento justas que cada signatário terá de implementar. O decreto Scapin $(2012)^{2}$ fortalece o sistema já em vigor no que diz respeito às penalidades ligadas ao não cumprimento da obrigação de igualdade profissional. Dispositivos mais específicos são projetados para atingir áreas de ação precisas. Na França, em 2009, nos estabelecimentos de ensino superior e de pesquisa, uma carta de igualdade entre homens e mulheres adere à luta contra estereótipos e discriminações, trabalha em favor do equilíbrio de gênero em diversos setores e convida à nomeação de um representante na instituição responsável pela implementação da carta. Contudo, os censos estatísticos realizados nas universidades francesas mostram uma realidade que ainda não atingiu as expectativas da implementação de compromissos de igualdade entre mulheres e homens. Um relatório produzido pelo Ministério do Ensino Superior e da Pesquisa em $2018^{3}$ aponta que as mulheres representavam 24\% das professoras universitárias (PR) e $44 \%$ das mestres de conferência (MCF), ${ }^{4}$ em 2017. Somente $12 \%$ das mulheres ocupavam o cargo de reitora da universidade e $6 \%$ delas assumiam a presidência de órgãos públicos de pesquisa. No entanto, tendo em conta o processo histórico, o lugar das mulheres no mundo do trabalho está em expansão. Podemos falar de vent dans le ciel de plomb $b^{5}$ (Schweitzer, 2009). Se esse progresso tiver continuidade, uma distribuição igual de homens e mulheres será estabelecida em 2027 para os(as) MCF. Quanto ao corpo de professores universitários, com menos progresso, a igualdade entre homens e mulheres deve ocorrer em 2068.

Apesar desses avanços na instauração da igualdade entre mulheres e homens no mundo do trabalho, uma metáfora surge para explicar os obstáculos que as mulheres enfrentam quando desejam progredir na hierarquia em termos de status profissional, tanto no setor público quanto no privado (Marry \& Pochic, 2017): o fenômeno do teto de vidro, que ilustra as barreiras invisíveis decorrentes de preconceitos comportamentais e processos organizacionais que prejudicam as mulheres em suas tentativas de acessar posições de responsabilidade, não porque lhe faltem competência, mas unicamente por causa do seu gênero. Esses preconceitos comportamentais dizem respeito à falta de ambição das mulheres e ao forte envolvimento com suas vidas privadas. Os processos organizacionais, por sua vez, referem-se à divisão do trabalho que relega às mulheres as tarefas menos privilegiadas, promoção de pares entre elas e inserção mínima das mulheres em redes-chave que facilitam a ascensão a posições de responsabilidade (Latour, 2008). Esse fenômeno ainda é muito presente no ensino superior e na pesquisa (Marry \& Jonas, 2005, Drucker-Godard et al., 2017).

1 http://www.afccre.org/mailing/Charte-égalité-FR.pdf

2 https://www.legifrance.gouv.fr/affichTexte.do?cidTexte=JORFTEXT000026792583\&categorieLien=id

3 https://www.enseignementsup-recherche.gouv.fr/pid38153-cid127382/www.enseignementsup-recherche.gouv.fr/ cid127382/esri-chiffres-cles-de-l-egalite-femmes-hommes-parution-2018.html

4 A inserção em postos de docência não temporários, na França, é iniciada no cargo de Maître de Conférences (MCF). Nessa categoria, o(a) profissional ministra aulas, mas não pode orientar doutorandos(as). Esse direito Ihes é conferido após obtenção do diploma Habilitation à Diriger les Recherches (HDR). Apenas de posse desse diploma é possível participar de concurso para Professeur des Universités (PR), que corresponde à categoria mais elevada da docência universitária.

5 A autora identifica que há progresso na ocupação de mulheres em profissões predominantemente masculinas (vent), mas observa também a existência de limites representados por tetos de vidro e céus de chumbo (cieux de plombe). 
Uma metáfora específica foi atribuída a esse campo, chamada de leaky pipeline (Alper \& Gibbons, 1993; Berryman, 1983). Ela denuncia a redução progressiva de mulheres após conclusão de seus estudos, de maneira contínua e reforçada quanto mais avançam na carreira acadêmica (Faniko et al., 2018), ainda que a maioria das estudantes de graduação e mestrado possua melhor formação acadêmica (Drucker-Godard et al., 2017). A metáfora leaky pipeline remete igualmente ao scissors effect, em português efeito tesoura (Boutillier \& Laperche, 2007), que representa a ação segundo a qual dois fenômenos evoluem em direções opostas. Assim, as mulheres sentem o limite das possibilidades de promoção da carreira mais fortemente do que os homens (Drucker-Godard et al., 2017). Finalmente, se a presença de mulheres em cargos hierárquicos de responsabilidade é maior no serviço público do que no setor privado (Alber, 2013), conseguir obter uma Habilitação para Dirigir Pesquisas, no caso do ensino superior francês, não significa uma promessa de não mais sofrer desigualdades no cargo de categoria mais elevada. Rossiter (1995) fala do efeito Matilda para se referir a uma sub-representação das contribuições científicas das mulheres em favor dos homens. Como exemplo, podemos observar que 784 prêmios Nobel foram concedidos, entre 1901 e 2006, e apenas 34 foram para mulheres (Boutillier \& Laperche, 2007). As mulheres também tendem a receber menos espaço de pesquisa (e.g. escritórios) e financiamento para seus trabalhos do que os homens (Ellemers et al., 2004).

\section{O papel das mullheres na construção das desigualdades profissionais}

Tudo parece indicar que o homem é um ator direto na construção da desigualdade entre homens e mulheres no mundo profissional com forte dominação masculina (Brenner et al., 1989). No entanto, trabalhos recentes (Derks et al., 2011; Ellemers et al., 2004; Faniko et al., 2016; Faniko et al., 2017b) destacam a parte de responsabilidade que as mulheres possuem na construção dessas desigualdades profissionais. Esses autores pegaram emprestado de Staines et al. (1974) o termo abelha-rainha (AR) para descrever três características atitudinais que uma mulher, que ocupa um posto de responsabilidade, pode adotar, impactando assim o avanço hierárquico de mulheres em postos subordinados a ela (Faniko et al., 2018).

Uma dessas características é a assimilação de traços masculinos. Esse efeito decorre da necessidade, para as mulheres em posição de poder, de se inscreverem no modelo dominante baseado em estereótipos de gênero masculino, ou seja, traços ditos agency (e.g. dominante, independente), para serem qualificadas e avaliadas mais positivamente (Derks et al., 2011). Também é necessário se distanciar das mulheres (e.g. mulheres no início de suas carreiras ou em posições subordinadas) que provavelmente continuarão a confirmar os estereótipos de gênero que as mulheres em posições de poder se esforçaram tanto para combater: por exemplo, de que o sucesso para a mulher deve-se à sorte enquanto para o homem é decorrente de sua competência; de que a mulher é menos engajada do que o homem e menos competente; e mais ainda quando elas devem conciliar vida profissional e familiar (Ellemers et al., 2004; Faniko et al., 2017b). Ao mesmo tempo, elas continuam a se identificar com mulheres da mesma posição estatutária, porque estas conseguiram dissipar estereótipos negativos alcançando cargos de alto status (Faniko et al., 2016). Essa outra característica, o distanciamento de mulheres em postos de responsabilidade em direção a mulheres subordinadas, é observada por meio da percepção de seu compromisso, de sua ambição e dos sacrifícios feitos em sua carreira como superiores aos de suas colegas subordinadas (Faniko et al., 2016, 2017a).

A legitimação da hierarquia de gênero, terceira característica do efeito abelha-rainha, aponta que as atitudes da abelha-rainha podem ser usadas para legitimar a desigualdade de gênero. Essa legitimação se apresenta de várias maneiras, por exemplo: negando a discriminação de gênero sofrida por mulheres e a desvantagem estrutural em decorrência de seu gênero; não apoiando (ou mesmo sendo contrárias) as políticas afirmativas de combate à discriminação que são postas em 
prática para promover o avanço das mulheres em suas carreiras, especialmente para mulheres juniores em uma posição subordinada; e reforçando o discurso da meritocracia segundo o qual aqueles(as) que se esforçam mais, são mais ambiciosos(as), possuem menos obrigações familiares e trabalham arduamente conseguem obter melhores posições. Gibson e Cordova (1999) pensam que as mulheres em postos de responsabilidade querem manter as organizações tais como elas são (i.e. organizações nas quais dominam os estereótipos de gênero masculino) porque elas conseguiram se impor nesse ambiente ainda que as barreiras fossem dificilmente transponíveis, sendo que destruí-las agora seria aniquilar seus esforços anteriores para alcançá-las. Além disso, as mulheres que tiveram sucesso no passado em condições de acesso ainda mais herméticas do que as encontradas hoje são as mais categoricamente contrárias à implementação de políticas de ações afirmativas para as mulheres jovens (Derks et al., 2011; Ellemers et al., 2004).

A metáfora da abelha-rainha que descreve uma discriminação direta de algumas mulheres em posição de poder contra suas subordinadas é na verdade uma consequência indireta de discriminações e desigualdades primeiramente vivenciadas por essas mulheres (Derks et al., 2016). O fenômeno abelha-rainha não é entendido como uma competição entre mulheres, mas sim como uma forma de algumas mulheres em postos de responsabilidade mostrarem sua ambição em organizações consideradas sexistas (Derks et al., 2011), nas quais para ter sucesso deve-se modelar sua atitude e comportamento de acordo com os padrões atuais: os dos homens. No entanto, nem todas as mulheres em cargos de poder desenvolvem as características de uma abelha-rainha, algumas contribuem, ao contrário, para aumentar a proporção de mulheres em cargos de alto nível estatutário, desde sua chegada a um cargo de responsabilidade (Arvate et al., 2018).

A literatura identifica duas categorias de determinantes na origem desse efeito. Uma é contextual: o fenômeno abelha-rainha (i.e. as características vistas anteriormente) aparece, na maioria dos casos, em organizações em que predominantemente homens ocupam cargos de responsabilidade (Derks et al., 2016). A outra está ligada ao percurso pessoal da mulher: a escolha dessa estratégia vai depender da percepção da mulher quanto à complexidade para ascender na hierarquia e do grau de identificação que ela possui com o grupo social de mulheres (Derks et al., 2016).

Um estudo com mulheres em cargos de poder em diferentes organizações dos setores público e privado na Holanda mostra uma correlação significativa entre a identificação de gênero e a experiência de discriminação. As mulheres que menos se identificam com outras mulheres são as que expressam a maior taxa de negação de discriminação no local de trabalho no passado. Por outro lado, as mulheres que mais se identificam com seu gênero testemunham com maior frequência terem sido vítimas de discriminação em suas carreiras profissionais. Além disso, as mulheres que mais foram discriminadas e que têm uma forte identificação masculina exibem um maior nível de comprometimento (Derks et al., 2011).

\section{O efeito abelha-rainha na universidade}

Ainda que o efeito abelha-rainha tenha sido amplamente analisado nas últimas duas décadas, sua observação no campo acadêmico do ensino superior e da pesquisa permanece pouco documentada. No entanto, os trabalhos existentes tendem a mostrar que esse efeito está também presente nas universidades: assimilação de características masculinas e distanciamento de mulheres subordinadas (doutorandas) são notados entre as mulheres mais seniores (professoras) em universidades na Itália e Holanda (Ellemers et al., 2004), mostrando que, embora doutorandos e doutorandas se considerassem iguais em suas carreiras e em seu comprometimento, as professoras percebiam as doutorandas, mais do que os doutorandos, como menos comprometidas com suas carreiras do que elas próprias eram no início de suas carreiras.

O presente estudo tem como objetivo explorar a ocorrência das características desse fenômeno em uma universidade francesa, observando, em particular, se esse efeito se manifesta de diferentes 
formas de acordo com a filiação a um dos dois corpos profissionais que constituem a comunidade universitária: docentes-pesquisadores(as) cujas duas categorias estatutárias são MCF e PR; e pessoal não docente, nomeadamente engenheiros, pessoal administrativo, técnico, social e de saúde e de bibliotecas (i.e. Biatss) ${ }^{6}$ que se enquadram em três categorias estatutárias (A, B e C).

Mais especificamente, espera-se maior assimilação de traços masculinos em mulheres de alto status (PR e Biatss categoria A) do que em mulheres MCF e Biatss categorias B e C. Também se espera um distanciamento das mulheres de alto status em relação a suas colegas subordinadas, incluindo as dimensões de comprometimento, sacrifício pessoal e a mbição, bem como uma negação da discriminação e atitudes desfavoráveis no que se refere às políticas de ação afirmativa. Essas características do efeito abelha-rainha são mais esperadas em mulheres do que em homens, independentemente da categoria ocupacional a que pertençam.

\section{Método}

\section{Contexto do estudo}

Embora de dimensão média (cerca de 28.000 alunos para 3.000 funcionários em todas as categorias), a Universidade de Poitiers, fundada em 1431, é conhecida pela sua influência cultural, científica e econômica, pela sua oferta formativa multidisciplinar, bem como pela taxa de sucesso dos alunos e pela qualidade da recepção. Essa universidade, membro da Carta, desde 2014 tem liderado ações que favorecem a igualdade e a diversidade entre funcionários e alunos (e.g. inventário estatístico anual, campanhas de conscientização). Ela também é membro da Conferência Permanente de Oficiais de Igualdade e Diversidade (CPED), uma associação que se dedica com mais afinco à luta pela igualdade dentro das universidades (Texier-Picard, 2011). Os docentes titulares de todas as disciplinas contabilizam 909 funcionários, dos quais 36,5\% são mulheres. Apenas uma Unidade de Formação e Pesquisa possui parte majoritária e significativa das mulheres, a de Letras e Línguas, com mais de 57,8\% de mulheres. Deve-se notar que, em comparação com 2015, algu mas disciplinas viram seus percentuais de mulheres docentes-pesquisadoras diminuir; por outro lado, o número de mulheres aumentou em áreas como medicina, ciências da computação e humanidades. As mulheres representam $42,9 \%$ de MCF e 20,3\% de PR, que está acima da média nacional.

\section{Participantes da pesquisa (amostra)}

Vinte e duas entrevistas semidiretivas foram realizadas, por três entrevistadoras, com funcionários da Universidade de Poitiers. Foram entrevistados(as) docentes-pesquisadores(as) $(\mathrm{DP}, \mathrm{n}=9$ ) e pessoal não docente (Biatss, $\mathrm{n}=13$ ). Eles(as) foram contatados(as) por e-mail para participar de uma pesquisa sobre as condições de trabalho de homens e mulheres na universidade. Em caso de resposta positiva ao convite, um encontro individual era agendado nas dependências da universidade para uma entrevista, com duração média de 40 minutos. Todos os participantes deveriam primeiro assinar um termo de consentimento livre e esclarecido que descrevia o escopo do estudo, garantia seu anonimato e sigilo e solicitava o consentimento para a gravação da entrevista. As características sócio-ocupacionais dos(as) entrevistados(as) são apresentadas no Quadro $1 .^{7}$

6 Esse acrônimo, em francês, refere-se a um grupo de ocupações da função pública que trabalha em diferentes campos: bibliotecas (B), engenheiros (I), administradores (A), pessoal técnico (T), serviços sociais e de saúde (SS).

7 Quanto à escolaridade, há nomenclaturas francesas que não encontram correspondentes no Brasil. Brevet d'études professionnelles (BEP) consiste em um diploma intermediário do bacharelado profissional obtido após três anos de estudo. O sistema superior na França segue o padrão do sistema europeu chamado Licenciatura, Mestrado e Doutorado (LMD). Os tempos médios para conclusão desses níveis são de 3, 5 e 8 anos, respectivamente. Ao final de cada ano de estudo, pode-se acumular um diploma que varia de Bac +3 (conclusão licenciatura) a Bac +8 (conclusão do doutorado). 
QUADRO 1

CARACTERIZAÇÃO DOS(AS) PARTICIPANTES

\begin{tabular}{|c|c|c|c|c|c|c|c|c|c|}
\hline & Gênero & $\begin{array}{l}\text { Faixa } \\
\text { etária }\end{array}$ & Cargo & Nível & Escolaridade & $\begin{array}{l}\text { Tempo } \\
\text { na UP }\end{array}$ & $\begin{array}{c}\text { Horas } \\
\text { trabalhadas/ } \\
\text { semana }\end{array}$ & Estado civil & Filhos \\
\hline E01 & $\mathrm{F}$ & $46-50$ & Biatss & C & $\mathrm{Bac}+2$ & 3 anos & $38 \mathrm{~h}$ & Casada & 2 \\
\hline E02 & $\mathrm{F}$ & $46-50$ & $D-P$ & PR & Doutorado & 20 anos & $45 h-55 h$ & Casada & 1 \\
\hline E03 & $\mathrm{F}$ & $31-35$ & Biatss & A & Mestrado & 6 anos & $40 h-45 h$ & Casada & 2 \\
\hline E04 & $\mathrm{F}$ & $36-40$ & $D-P$ & PR & Doutorado & 8 anos & $60 \mathrm{~h}$ & Solteira & 0 \\
\hline E05 & $\mathrm{F}$ & $36-40$ & $D-P$ & PR & Doutorado & 9 anos & $45 \mathrm{~h}-50 \mathrm{~h}$ & Casada & 2 \\
\hline E06 & $\mathrm{F}$ & $>55$ & Biatss & C & BEP & 38 anos & $38 \mathrm{~h}$ & Casada & 2 \\
\hline E07 & $\mathrm{F}$ & $>55$ & Biatss & B & BEP & 35 anos & $38 \mathrm{~h} 05$ & Casada & 2 \\
\hline E08 & $\mathrm{F}$ & $36-40$ & $D-P$ & MCF & Doutorado & 2 anos & $40-50 \mathrm{~h}$ & Casada & 2 \\
\hline E09 & $\mathrm{F}$ & $36-40$ & Biatss & B & $\mathrm{Bac}+4$ & 14 anos & $38 \mathrm{~h} 30$ & Divorciada & 3 \\
\hline E10 & $\mathrm{F}$ & $41-45$ & Biatss & C & Licence & 6 anos & $38 \mathrm{~h} 30$ & Casada & 3 \\
\hline E11 & $\mathrm{F}$ & $31-35$ & Biatss & C & Mestrado & 4 anos & $38 \mathrm{~h} 05$ & Solteira & 0 \\
\hline E12 & $\mathrm{F}$ & $36-40$ & Biatss & C & BEP & 7 anos & $45 \mathrm{~h}$ & União estável & 2 \\
\hline E13 & $\mathrm{F}$ & $>55$ & $D-P$ & PR & Doutorado & 16 anos & $50 \mathrm{~h}$ & Casada & 2 \\
\hline E14 & $\mathrm{F}$ & $>55$ & $D-P$ & $\mathrm{MCF}$ & Doutorado & 20 anos & $40 \mathrm{~h}$ & União estável & 2 \\
\hline E15 & $\mathrm{F}$ & $46-50$ & Biatss & A & $\mathrm{Bac}+2$ & 21 anos & $38 \mathrm{~h} 05$ & Solteira & 0 \\
\hline E16 & $\mathrm{M}$ & $31-35$ & Biatss & B & $\mathrm{Bac}+2$ & 11 anos & $38 \mathrm{~h} 05$ & União estável* & 0 \\
\hline E17 & $\mathrm{M}$ & $51-55$ & Biatss & A & Mestrado & 6 anos & $40-50 \mathrm{~h}$ & Casado & 3 \\
\hline E18 & $\mathrm{M}$ & $51-55$ & Biatss & C & $\mathrm{Bac}$ & 21 anos & $38 \mathrm{~h}$ & União estável & 3 \\
\hline E19 & $\mathrm{M}$ & $36-40$ & Biatss & A & Mestrado & 13 anos & $40 \mathrm{~h}-50 \mathrm{~h}$ & União estável* & 2 \\
\hline E20 & $\mathrm{M}$ & $51-55$ & $D-P$ & PR & Doutorado & 8 anos & $40 h-50 h$ & Divorciado & 4 \\
\hline E21 & $\mathrm{M}$ & $41-45$ & $D-P$ & PR & Doutorado & 8 anos & $50 \mathrm{~h}$ & União estável & 3 \\
\hline E22 & M & $36-40$ & $D-P$ & $\mathrm{MCF}$ & Doutorado & 3 anos & $40 \mathrm{~h}$ & União estável* & 2 \\
\hline
\end{tabular}

Fonte: Elaboração das autoras.

*União estável oficializada pelo Pacto Civil de Solidariedade (Pacs).

A amostra de docentes-pesquisadores(as) foi composta por seis mulheres e três homens (idade: $M=46,1$ anos, $D P=8,2$; anos de experiência no ensino e pesquisa: $M=10,4, D P=6,7$ ), dos quais três são MCF (duas mulheres e um homem) e seis PR (quatro mulheres e dois homens). A amostra de funcionários não docentes (Biatss) foi composta por nove mulheres e quatro homens (idade: $M=43,8$ anos, $D P=8,8$; anos de carreira: $M=14,5, D P=11,5$ ), dos quais seis são da categoria $\mathrm{C}$ (cinco mulheres e um homem), três pertencem à categoria $\mathrm{B}$ (duas mulheres e um homem) e quatro da categoria A (duas mulheres e dois homens). Apenas um dos participantes possuía também experiência profissional no setor privado.

\section{Roteiro da entrevista}

A coleta de dados foi realizada na forma de entrevista semidiretiva, a fim de permitir a expressão de um discurso espontâneo sobre temas direcionados pelos objetivos do estudo. Os(as) participantes responderam às mesmas perguntas para fins de comparação dos dados, mas, conforme o grupo profissional ao qual pertenciam e ao gênero, algumas palavras ou ordem das questões eram modificadas. Uma primeira etapa consistiu em acessar dados sociodemográficos (estado civil, idade, nível de escolaridade) e profissionais (nível estatutário, cargo ocupado, antiguidade no cargo, antiguidade profissional na universidade, tempo de trabalho semanal) dos participantes, 
bem como autoavaliação do nível de carreira com base em uma escala que variava de 1 (muito iniciante) a 5 (muito sênior). $\mathrm{Na}$ segunda parte da entrevista, foram feitas perguntas sobre os temas do estudo. Um primeiro roteiro de entrevistas foi submetido a quatro funcionários não participantes do estudo principal - dois docentes-pesquisadores(as) e dois funcionários(as) não docentes. As revisões e ajustes visaram a chegar a formulações precisas, mas suficientemente amplas e compreensíveis para atrair nossos dois grupos-alvo da mesma forma. Igualmente, estas foram redigidas de modo a não direcionar as respostas. Ao final, o roteiro da entrevista abrangeu somente sete questôes, de modo a permanecer dentro do quadro de uma entrevista semidiretiva favorecendo a fluidez do discurso: quatro questões sobre comprometimento na carreira ("Como você descreveria seu comprometimento profissional?”, “O que é para você ter sucesso profissional na universidade?”, "Qual seria seu projeto profissional?”, "Vocêjá fez escolhas pessoais para atender a expectativas profissionais?”); uma questão sobre a percepção das qualidades necessárias para se ter sucesso na universidade (“O que você acha que é preciso para ter sucesso profissional na universidade?”) ; e duas questões sobre identificação profissional ("Você se identifica com mulheres ou homens que estão no mesmo nível estatutário que você? E com os que pertencem a um nível estatutário diferente?”).

\section{Análise de conteúdo das entrevistas}

Cada entrevista gravada foi transcrita na íntegra. A dupla codificação manual realizada em todo o corpus resultante das 22 entrevistas possibilitou a realização de uma análise de conteúdo temática e de frequência (Bardin, 2013), método escolhido para identificar, por meio da estrutura do discurso, a forma como os comentários se organizam em torno do objeto de estudo e para comparar os quatro grupos de mulheres considerados (DP vs Biatss $v s$ estatuto superior $v s$ estatuto inferior) com base nos mesmos critérios. Para tanto, extraíram-se categorias temáticas e depois subtemas (ou subcategorias), em função da frequência e da semelhança das unidades de sentido (ocorrências temáticas) identificadas ao longo do corpus, isto é, todas as entrevistas combinadas. Sobre esses elementos, diversas comparações foram feitas: entre as falas das mulheres segundo suas categorias profissionais (DP $v s$ Biatss) e no interior de suas categorias profissionais, entre funcionários de nível estatutário diferente (PR vs MCF para DP e categoria A vs categorias $\mathrm{B} / \mathrm{C}$ para Biatss). Os discursos dos homens foram recuperados segundo o mesmo roteiro de análise.

\section{Resultados}

A análise de conteúdo temática e de frequência possibilitou identificar ocorrências temáticas, classificadas em seis categorias, cada uma compreendendo duas a seis subcategorias (ver Quadro 2).

\section{QUADRO 2}

CATEGORIAS, SUBCATEGORIAS E OCORRÊNCIAS TEMÁTICAS RESULTANTES DA ANÁLISE DAS ENTREVISTAS

\begin{tabular}{|c|c|c|}
\hline Categorias & Subcategorias & Ocorrências temáticas \\
\hline \multirow{3}{*}{ Comprometimento profissional } & Notável & $\begin{array}{l}\text { Investimento além do que é necessário } \\
\text { Ter prazer na realização da tarefa }\end{array}$ \\
\hline & Moderado & $\begin{array}{l}\text { Fazer apenas o que é esperado } \\
\text { Redução do comprometimento }\end{array}$ \\
\hline & $\begin{array}{l}\text { Em função da natureza da } \\
\text { atividade }\end{array}$ & Pedagogia/pesquisa \\
\hline
\end{tabular}


(Continuação)

\begin{tabular}{|c|c|c|}
\hline Categorias & Subcategorias & Ocorrências temáticas \\
\hline \multirow{3}{*}{$\begin{array}{l}\text { Percepção de sucesso na } \\
\text { universidade }\end{array}$} & Sucesso pessoal & $\begin{array}{l}\text { Realização/amar seu trabalho } \\
\text { Manutenção de boas relações }\end{array}$ \\
\hline & Compromisso com o coletivo & $\begin{array}{l}\text { Cumprir suas missões } \\
\text { Ajudar a coletividade/fazer avançar as coisas }\end{array}$ \\
\hline & Sucesso profissional & $\begin{array}{c}\text { Promoção/progressão da carreira } \\
\text { Ter responsabilidades } \\
\text { Reconhecimento profissional }\end{array}$ \\
\hline \multirow{6}{*}{$\begin{array}{l}\text { Qualidades necessárias para o } \\
\text { sucesso na universidade }\end{array}$} & Comprometimento & Envolver-se/vontade \\
\hline & Competência & Conhecimento/capacidades \\
\hline & Legitimidade & Preconceito \\
\hline & Contexto de vida & $\begin{array}{l}\text { Mobilidade } \\
\text { Obrigações familiares } \\
\text { Sacrifício }\end{array}$ \\
\hline & Sorte & \\
\hline & Traços agency & Assertividade/se impor \\
\hline \multirow[t]{2}{*}{ Projeto profissional } & Internamente na universidade & $\begin{array}{l}\text { Responsabilidades coletivas } \\
\text { Progressão hierárquica } \\
\text { Progressão científica }\end{array}$ \\
\hline & Fora da universidade & $\begin{array}{l}\text { Projeto de mobilidade externa } \\
\text { Equilíbrio vida pessoal e profissional }\end{array}$ \\
\hline \multirow[b]{2}{*}{ Identificação profissional } & Presente & $\begin{array}{l}\text { Mesmo percurso } \\
\text { Mesmas responsabilidades } \\
\text { Mesmo trabalho a fazer } \\
\text { Mesmos obstáculos }\end{array}$ \\
\hline & Ausente & $\begin{array}{c}\text { Diferença em termos de escolha de vida privada } \\
\text { Diferença em termos de sacrifício } \\
\text { Diferença em termos de escolha de vida } \\
\text { profissional } \\
\text { Diferença em termos de oportunidades } \\
\text { profissionais }\end{array}$ \\
\hline \multirow{4}{*}{ Fatores de melhoria das carreiras } & $\begin{array}{l}\text { Igualdade de gênero na } \\
\text { universidade }\end{array}$ & $\begin{array}{l}\text { Correto em comparação com serviços privados } \\
\text { em andamento }\end{array}$ \\
\hline & Papel da universidade & $\begin{array}{l}\text { Creche/cuidado das crianças } \\
\text { Consideração das qualidades da mulher } \\
\text { Acompanhamento das mulheres }\end{array}$ \\
\hline & Papel da sociedade & $\begin{array}{l}\text { Mudança de costumes } \\
\text { Política de cotas }\end{array}$ \\
\hline & Papel da mulher & $\begin{array}{c}\text { Escolha, compromisso entre vida familiar e } \\
\text { profissional } \\
\text { Ter competências e currículo equivalentes aos } \\
\text { dos homens }\end{array}$ \\
\hline
\end{tabular}

Fonte: Elaboração das autoras.

\section{Discurso das mulheres docentes-pesquisadoras}

Quando se trata de definir seu comprometimento profissional, as professoras universitárias $(\mathrm{PR}, \mathrm{n}=4)$ evocam um investimento significativo em todos os componentes da profissão ("é um comprometimento total, ao mesmo tempo no âmbito educacional, de pesquisa e de gestão do 
estabelecimento" - E4). As MCF ( $\mathrm{n}=2$ ) falam, por sua vez, de um forte comprometimento com questões educacionais ("isso me preocupa muito, aliás, dar aulas que façam sentido, com reflexão pedagógica, que permita aos alunos aprenderem melhor” - E8). Por outro lado, dizem que é mais difícil investir em pesquisa por causa da falta de autonomia desse nível estatutário ("se sentir legítima como coordenadora de projetos e não apenas ser participante de projetos coordenados por outros" - E8). Para as PR, o sucesso na universidade requer que se passe por funções de responsabilidades coletivas ("se conseguirmos fazer as coisas para o coletivo, acho que é realmente ter sucesso" - E4), mas também por meio do sucesso pessoal ("antes ter sucesso significava conseguir subir na hierarquia, agora significa que você consegue trabalhar como quer e com o que gosta de fazer" - E2). Para as MCF, trata-se mais de cumprir corretamente as missões de ensino que lhes foram confiadas, mesmo à custa de suas progressões na carreira ("o mais útil para o avanço na carreira é, sem dúvida, investir em pesquisa, eu também investi, mas não gostaria de investir em pesquisa em detrimento da qualidade do ensino" - E8).

Tanto para as $\mathrm{PR}$ quanto para as MCF, as qualidades necessárias para uma mulher ter sucesso na universidade são competência e comprometimento ("um pouco obstinada e trabalhar muito, isso é indispensável” - E13), sendo essas qualidades em parte ditadas por uma série de preconceitos contra as mulheres ("acho que temos que mostrar que somos mais capazes que um homem e acho que isso vale na universidade como em qualquer lugar” - E4). Também evocam um contexto familiar que pode dificultar e/ou influenciar o sucesso das mulheres ("é verdade que é complicado quando você é mulher porque muitas vezes a mãe se ocupa mais dos filhos" - E2), bem como a necessidade de fazer sacrifícios ("nossos colegas homens riem se dissermos, por exemplo, às quartas-feiras prefiro ficar em casa" - E5). Elas se questionam sobre a legitimidade do seu lugar ("me sinto muito incomodada quando sou contactada para fazer parte de uma comissão, quando me dizem que sim, precisamos de paridade, nesse caso me pergunto, fui escolhida porque sou mulher, ou porque sou competente?" - E13). As qualidades necessárias a um homem para que ele obtenha sucesso na universidade são também, para a maioria das docentes--pesquisadoras, da ordem de comprometimento, mas de acordo com elas o contexto cultural é mais favorável para os homens, por um lado, em termos de legitimidade ("eu acho que os homens hesitam menos, eles se sentem mais legítimos em muitas situações, duvidam menos da sua capacidade de obter tal ou tal posto" - E8) e, por outro, no que concerne aos preconceitos ("ninguém imagina que eles não vêm nas quartas-feiras por causa dos filhos, quando eles não vêm, dizemos: bem, eles trabalham de casa e ponto final" - E5).

Os projetos profissionais das mulheres docentes-pesquisadoras podem estar conduzidos em direção seja de responsabilidades coletivas ("ter responsabilidades, como ser responsáveis pelo comitê científico ou educacional" - E5), seja de uma conquista científica ("continuar a encontrar coisas na pesquisa, encontrar bons resultados" - E4). Porém a maioria das PR optou por priorizar a carreira profissional em detrimento da vida pessoal ("Eu realmente me adapto ao cronograma da universidade” - E5), enquanto MCFs enfatizam a necessidade de manter um equilíbrio entre trabalho e vida pessoal. Em termos de identificação profissional, as PR - e não as MCF - se identificam com os homens de mesma posição estatutária que elas, ainda que apontem as diferenças no processo de aquisição do cargo ("os colegas homens se tornaram professores bem mais cedo que eu em suas carreiras, isso é evidente, depois, uma vez que estamos na mesma posição eu não vejo desigualdade de qualquer tipo" - E13). A maioria das docentes-pesquisadoras se identifica com outras mulheres da mesma posição estatutária ("Digo a mim mesma que elas também tiveram que se sacrificar e lutar” - E2), mas as $\mathrm{PR}$, contrariamente às $\mathrm{MCF}$, não necessariamente se identificam com mulheres de nível estatutário inferior ("não, não temos a mesma vida de jeito nenhum, lembro como era, mas atualmente se você me perguntar se me identifico, não. Me identifico mais com mulheres que têm o mesmo nível que eu” - E5). Finalmente, as PR consideram que a mulher possui papel central no desenvolvimento de sua carreira na universidade ("para mim, quando as mulheres não conseguem os postos que desejam na 
universidade, é mais porque elas fizeram uma escolha" - E5), que a igualdade entre homens e mulheres é respeitada na universidade ("ainda estamos de modo geral em melhor situação do que no setor privado; se falamos sobre gestão universitária como ela é, não sei o que podemos realmente mudar” - E13) e não são favoráveis às políticas de cotas. Para as MCF, a universidade tem o papel principal na melhoria da carreira das mulheres na instituição ("montar creches, que possibilitassem, por exemplo, o contato com a criança em um dia longo de trabalho" - E8).

\section{Discurso das mulheres Biatss}

As mulheres Biatss de categoria A ( $n=2)$ expressam comprometimento profissional considerável para o benefício de alunos e professores ("Eu fico à noite se eu tiver que ficar, às vezes eu levei trabalho para casa" - E7). Para as de categorias inferiores (B: $n=2$ e C: $n=5)$, trata-se essencialmente de permanecer dentro da estrutura do trabalho e cumprir as missões inerentes ao cargo. Para as mulheres de categoria A, o sucesso na universidade está estritamente ligado ao desenvolvimento pessoal ("estar em um posto de trabalho que você gosta com missões nas quais você se encontra" - E3). Para aquelas de categorias B e C, o sucesso passa essencialmente pela qualidade do serviço prestado ao coletivo ("trazer toda sua experiência para a universidade" - E9) e, de uma forma mais minoritária, pela promoção ("significa passar em concursos de categorias superiores para ter acesso a um salário mais adequado para mim” - E11).

As qualidades indispensáveis para as mulheres são, segundo elas, competências idênticas às dos homens, tendo em vista, em particular, a igualdade de critérios aplicados durante os concursos. No entanto, a maioria menciona que o contexto familiar pode retardar o sucesso profissional das mulheres. Com algumas exceções, as mulheres Biatss nas categorias $\mathrm{B}$ e $\mathrm{C}$ não têm projetos profissionais e estão satisfeitas com sua posição atual, principalmente no que diz respeito à segurança no emprego e à possibilidade de conciliar vida profissional e privada. Apenas uma minoria considera uma evolução de categoria por meio da aprovação em concurso. Em termos de identificações, as mulheres Biatss, independentemente de sua categoria estatutária, identificam-se com suas subordinadas ou colegas de nível superior (para a categorias B e C) em função das semelhanças de suas missões e atividades. Por fim, a maioria dessas mulheres acredita que o avanço da carreira feminina é responsabilidade da universidade.

\section{Discurso dos homens docentes-pesquisadores}

Os professores ( $\mathrm{PR}, \mathrm{n}=2)$ descrevem um importante comprometimento profissional ("eu tenho um comprometimento determinado, motivado, engajado" - E21). O sucesso na universidade se traduz antes de tudo, para eles, pela promoção estatutária ("ter sucesso na universidade é subir na hierarquia" - E21), depois pelo reconhecimento de suas qualidades profissionais ("ser reconhecido como um bom professor por seus estudantes e ser reconhecido como um bom pesquisador por seus colegas e, então, ser reconhecido como alguém comprometido com sua instituição" - E20). Esse ponto de vista é compartilhado pelo MCF ( $\mathrm{n}=1)$, mas ter sucesso também é, para ele, uma realização pessoal ("é também se realizar com o conjunto de suas atividades" - E20, "estar motivado por seu trabalho" - E21). Para esses três homens docentes-pesquisadores, as qualidades necessárias para o sucesso na universidade são semelhantes para homens e mulheres, porém os PR reconhecem que para as mulheres essas qualidades devem provavelmente aumentar de modo considerável para que o sucesso seja efetivo ("é necessário sem dúvida uma motivação maior, mais importante, uma determinação mais importante" - E20). Em relação à identificação profissional, os PR a relativizam em função do investimento profissional ("podemos nos identificar, sentir-nos próximos de pessoas que não pertencem ao mesmo estatuto profissional, mas que têm a mesma energia no trabalho, o mesmo desejo, de combinar paixão com trabalho" - E21). Os PR estimam que as mulheres possuem papel central no desenvolvimento de suas carreiras e que as políticas de cotas não são vantajosas para elas, ao passo que o MCF estima que a sociedade tem um papel inegável no avanço da carreira das mulheres ("deveria realmente haver uma mudança de mentalidades" - E22). 


\section{Discurso dos homens Biatss}

Os homens Biatss de categoria A ( $\mathrm{n}=2)$, bem como aqueles de categoria inferior $(B: n=1)$, exprimem um comprometimento profissional significativo ("é bastante nobre nos colocarmos a serviço de alunos, professores e pesquisadores para fornecer os recursos necessários para o avanço da ciência” - E17). Para eles, o sucesso na universidade passa antes de tudo pelo reconhecimento profissional e pela promoção na carreira ("progredir, subir na hierarquia gradualmente na minha carreira na universidade" - E16, "obter retorno positivo, na medida do possível, dos vários parceiros e usuários que são afetados pelos serviços que oferecemos" - E19) e nenhum deles menciona o sacrifício pessoal ou profissional inerente a seus cursos ("até agora, minha carreira nunca influenciou minhas escolhas" - E16). Todos eles se identificam profissionalmente com homens de estatuto inferior ou superior em função da semelhança de missões. Todos acreditam que uma profunda mudança social é necessária para o desenvolvimento da carreira das mulheres, mesmo que acreditem que uma certa equidade de tratamento está presente na universidade (“o serviço público garante igualdade de tratamento no recrutamento" - E16).

\section{Discussão}

O fenômeno abelha-rainha é observável na universidade sob suas três características, conforme descrito na literatura recente (Faniko et al., 2016, 2017b)? Para responder a essa pergunta, o presente estudo qualitativo consistiu em identificar atitudes no discurso das mulheres representativas de uma comunidade universitária francesa que consistem em adotar características estereotipadas masculinas (aderência a traços agency, tais como alto compromisso de carreira e sacrifício pessoal para promover a progressão na carreira), apresentar baixa identificação com as mulheres em cargos da base da hierarquia e no início de suas carreiras e legitimar a hierarquia de gênero (negação da discriminação, valorização da meritocracia, hostilidade às políticas de cotas). Os resultados são discutidos em função das características mencionadas.

A respeito da assimilação de características estereotipadas masculinas, traços agency como a assertividade e a capacidade de afirmação foram identificados no discurso feminino como características necessárias para o sucesso na universidade. Com relação ao engajamento, ao comparar as respostas das professoras e MCF, as primeiras indicaram engajamento mais amplo envolvendo ensino, pesquisa e atividades administrativas na universidade, enquanto para MCF o compromisso, embora igualmente indicado como forte (tempo dedicado ao trabalho considerado importante), é dirigido principalmente para o campo do ensino. Para a maioria das entrevistadas Biatss, o tempo de trabalho inclui o período formal e legalmente designado para tal e o comprometimento delas está ligado ao cumprimento das missões a eles confiadas. Por outro lado, as mulheres acadêmicas enfatizaram os sacrifícios pessoais feitos para lidar com as exigências profissionais, tais como viagens, adiamento da licença maternidade e tempo dedicado ao trabalho durante as férias. As mulheres Biatss categoria A declararam haver feito sacrifícios ocasionais, por exemplo, para passar no concurso, e as das categorias $\mathrm{B}$ e $\mathrm{C}$ apenas enfatizaram a necessidade de ajustes diários em virtude das obrigações familiares.

Em resumo, apenas as mulheres acadêmicas, e entre elas mais professoras do que MCF, aderem a características estereotipadas masculinas baseadas na ambição profissional em termos de pesquisa e responsabilidades coletivas. $\mathrm{Na}$ opinião das professoras, essas atitudes garantem sua autonomia, legitimidade, desenvolvimento de carreira e, portanto, o sucesso na universidade. Entretanto, essas mulheres observam que o contexto profissional continua desfavorável a elas em relação ao progresso na carreira de seus colegas homens.

Conforme esperado, as professoras se identificam com as mulheres, assim como com os homens no mesmo nível estatutário que elas, mas têm pouca ou nenhuma identificação com as mulheres 
em níveis inferiores ou juniores. Apoiando o discurso meritocrático, elas enfatizam sua própria determinação e responsabilidade pelo sucesso acadêmico que obtiveram e minimizam a determinação socioprofissional favorável a seus pares homens. Essas atitudes não são encontradas entre as mulheres Biatss, incluindo as de categoria A.

$\mathrm{Na}$ mesma linha, os comentários das professoras estão de acordo com a legitimação da hierarquia de gênero: elas são reticentes quanto às políticas de cotas que ameaçam negar suas habilidades profissionais e minimizam a existência de uma organização fundada sobre o pertencimento a gênero dentro da universidade, ao contrário do que poderia acontecer no setor privado. No entanto, duas ambiguidades são observadas. Por um lado, a meritocracia é um forte valor defendido pelas mulheres acadêmicas, mas, por outro lado, elas reconhecem que, de acordo com estatísticas universitárias, estão em minoria em certos campos, tais como STEM (ciência, tecnologia, engenharia e matemática), e na categoria de professores, o que as impede de participar de áreas estratégicas nas quais ocorrem as tomadas de decisões universitárias. Também, enquanto as mulheres acadêmicas, de modo geral, defendem os valores de igualdade levados a cabo por suas universidades, algumas relatam logo experiências de discriminação. As mulheres Biatts descrevem contexto de trabalho menos hostil do que o das mulheres acadêmicas, já que seu ambiente profissional é composto predominantemente por mulheres que, salvo raras exceções, não demonstram desejo de desenvolvimento profissional. Seu contexto de trabalho é, consequentemente, menos competitivo e, portanto, menos discriminatório.

Como esperado, tanto para os acadêmicos quanto para homens Biatss, as características agency (forte compromisso profissional, valor profissional por meio de promoção estatutária e reconhecimento pelos pares) são garantias de sucesso profissional. Todos os discursos feitos por homens, acadêmicos e Biatss, refletem o apoio a uma política de defesa da igualdade entre homens e mulheres no trabalho, igualdade que eles acreditam ser implementada em sua comunidade acadêmica (recrutamento e promoção com base em critérios objetivos de competência). Eles reconhecem, no entanto, as dificuldades que colegas mulheres podem enfrentar.

Em resumo, de acordo com nossa hipótese, as atitudes características do fenômeno abelha-rainha são mais observadas entre as mulheres de alto status, mas somente entre as acadêmicas, ou seja, as professoras universitárias. Esses resultados, provenientes de uma universidade francesa, estão de acordo com os encontrados em outras universidades europeias, na Itália e na Holanda (Ellemers et al., 2004). Eles também apontam para uma clivagem dentro da comunidade de mulheres na universidade: enquanto o efeito abelha-rainha é percebido entre mulheres acadêmicas, ele não o é entre mulheres Biatss. Essa diferença observada entre as categorias pode ser interpretada de diferentes maneiras. Como descrito por Jacquemart e Sarfati (2016) com base em uma grande pesquisa realizada em 2014 entre docentes e pesquisadores, técnicos e pessoal administrativo do ensino superior e pesquisa, as categorias profissionais administrativas, no mundo universitário, são menos valorizadas do que as do ensino e pesquisa, e essa menor valorização induz diferentes relações subjetivas no trabalho.

Mais especificamente no campo do ensino superior e da pesquisa, temos análises sociológicas e socioeconômicas particularmente esclarecedoras das políticas públicas recentes. Em 2015, o governo francês decidiu impor uma cota de mulheres nos comitês de recrutamento e promoção universitária. Entretanto, esse tipo de política de paridade baseada em uma visão puramente aritmética não produz os resultados esperados em termos de igualdade de carreira entre homens e mulheres: a presença de mulheres em comitês de recrutamento ou promoção não favorece necessariamente o recrutamento efetivo de mulheres e pode até prejudicar suas carreiras, como mostra um artigo recente de um economista de universidades francesas (Deschamps, 2018). Constatando que esse efeito deletério é especificamente observado em comitês chefiados por homens, o pesquisador coloca a hipótese de que essa situação é em parte o resultado de uma atitude desfavorável dos homens em relação a essa reforma. Ele também aponta uma correlação surpreendente que pode evocar o efeito abelha-rainha: 
quanto maior a proporção de mulheres em um comitê, menor a classificação das candidatas, independentemente da qualidade de seus currículos. Finalmente, ele observa que essa reforma não tem incentivado mais mulheres a se candidatarem a postos de professoras.

Nessa perspectiva, Revillard (2014) apoia a hipótese de que a menor propensão das mulheres a se candidatarem a postos de professoras universitárias $30 \%$ a $40 \%$ menos que os homens, com características acadêmicas e científicas idênticas) pode ser explicada, por um lado, por uma menor confiança e/ou um menor gosto pela competição e, por outro, pela antecipação da discriminação(Bosquet et al., 2019). Essa atitude de autocensura por parte das mulheres estaria ligada a uma falta de "confiança relacionada ao papel profissional" antecipada (professional role confidence), conforme observado nos domínios STEM (Cech et al., 2011). Esse conceito enfatiza as expectativas dos papéis, habilidades e traços de identidade característicos de uma profissão, os quais as mulheres podem enfrentar. No caso de expectativas de gênero masculino, as mulheres podem escolher o caminho do evitamento, ou da assimilação de características e atitudes masculinas, conforme observado no fenômeno abelha-rainha.

Verdade que, na França, o acesso a empregos na função pública, bem como o desenvolvimento e oportunidades de carreira, é regulamentado por concursos nacionais tanto para cargos administrativos e técnicos (posições Biatss) quanto para os de ensino e pesquisa. Entretanto, é altamente provável que as carreiras acadêmicas promovam atitudes e, portanto, discursos que advoguem o individualismo e a responsabilidade individual em detrimento do questionamento do contexto de trabalho, satisfazendo assim uma norma social bem conhecida na psicologia social, a norma da internalidade que valoriza socialmente as explicações que envolvem o ator como fator causal em termos de comportamentos e de reforços (Beauvois, 2005; Dubois, 1994). Essa perspectiva teórica socionormativa enfatiza os desafios ideológicos envolvidos na problemática do efeito abelha-rainha e nos convida a vislumbrar um novo trabalho empírico. Pesquisas futuras permitiriam lançar luz sobre uma questão identificada por esse estudo: a contradição entre um discurso meritocrático das mulheres acadêmicas e sua experiência de sub-representação em cargos de responsabilidade e a discriminação indireta que elas admitem sofrer.

\section{Limitações e estudos futuros}

Este estudo é o primeiro a explorar manifestações do efeito abelha-rainha em uma universidade francesa. Nesse sentido, ele apresenta um caráter exploratório e possui limitações relacionadas em particular à sua natureza qualitativa. É muito provável que esses dados, originários de autorrelatos, estejam incorporados de desejabilidade social, que leva à camullagem das dificuldades pessoais e profissionais sentidas. Além disso, algumas categorias profissionais estão numericamente pouco representadas. Esse é o caso dos respondentes homens, mas igualmente de mulheres MCF. Aumentar o tamanho da nossa amostra em um estudo futuro poderia facilitar a emergência de efeitos que não surgiram na presente investigação e, assim, dar suporte à análise. Ainda, isso poderia trazer uma nuance ao dualismo de respostas por vezes observado para os dois grupos de participantes. A coleta de dados adicional deverá ser efetuada em outra universidade com características diferentes das de Poitiers, notadamente em termos de influência nacional e dimensão (por exemplo, uma universidade parisiense). Será necessário igualmente replicar esses padrões de resposta com dados quantitativos que apoiem as nossas observações qualitativas iniciais. Nessa perspectiva, o desenvolvimento de um instrumento do tipo questionário, baseado nas escalas disponíveis na literatura recente sobre o efeito de abelha-rainhae adaptado à comunidade acadêmica, permitirá também realizar estudos comparativos entre mulheres e homens de diferentes categorias profissionais e estatutos nas universidades de diferentes países. Esses estudos futuros tornarão possível analisar os prováveis determinantes culturais do efeito abelha-rainha. 


\section{Considerações finais}

O tema das relações de poder entre as mulheres é pouco estudado na literatura sobre as desigualdades de gênero nas carreiras, especialmente no mundo acadêmico. Além disso, comparar as mulheres docentes-pesquisadoras com as que trabalham na administração nunca foi, segundo nosso conhecimento, considerado no campo da pesquisa em psicologia social. Essa dupla abordagem destaca a heterogeneidade das posturas das mulheres em relação às questões de desigualdades e discriminação na carreira, mas também torna possível analisar o papel da instituição na produção ou limitação dessas desigualdades.

$\mathrm{Na}$ academia, como em outras organizações dos setores público e privado, as desigualdades de gênero são claramente multifatoriais. Ao especificar as condições para o surgimento e desenvolvimento do fenômeno abelha-rainha, fator de discriminação, entre outros, este estudo e os desenvolvimentos subsequentes que ele permite ajudarão a prevenir os efeitos negativos dos estereótipos de gênero e todas as formas de sexismo que podem prejudicar o desenvolvimento da carreira das mulheres no meio acadêmico e seu bem-estar no trabalho.

\section{Referências}

Alber, A. (2013). Un plafond de verre plus bas dans la fonction publique? Travail, Genre et Sociétés, 2, 131-154. Alper, J., \& Gibbons, A. (1993). The pipeline is leaking women all the way along. Science, 260(5106), 409-412. Arvate, P. R., Galilea, G. W., \& Todescat, I. (2018). The queen bee: a myth? The effect of top-level female leadership on subordinate females. The Leadership Quarterly, 29(5), 533-548.

Bardin, L. (2013). L'analyse de contenu. Presses Universitaires de France.

Beauvois, J.-L. (2005). Lesillusions libérales, individualisme et pouvoir social. Presses Universitaires de Grenoble.

Berryman, S. E. (1983). Who will do science? Trends, and their causes in minority and female representation among holders of advanced degrees in science and mathematics. A Special Report.

Bosquet, C., Combes, P.-P., \& García-Peñalosa, C. (2019). Gender and promotions: Evidence from academic economists in France. The Scandinavian Journal of Economics, 121(3), 1020-1053.

Boutullier, S., \& Laperche, B. (2007). La place des femmes dans la recherche: Apprentissage, production et valorisation des connaissances. Marché et Organisations, 3, 61-77.

Brenner, O. C., Tomkiewicz, J., \& Schein, V. E. (1989). The relationship between sex role stereotypes and requisite management characteristics revisited. Academy of Management Journal, 32(3), 662-669.

Cech, E., Rubineau, B., Silbey, S., \& Seron, C. (2011). Professional role confidence and gendered persistence in engineering. American Sociological Review, 76(5), 641-666.

Derks, B., Ellemers, N., Van Laar, C., \& De Groot, K. (2011). Do sexist organizational cultures create the queen bee? British Journal of Social Psychology, 50(3), 519-535.

Derks, B., Van Laar, C., \& Ellemers, N. (2016). The queen bee phenomenon: Why women leaders distance themselves from junior women. The Leadership Quarterly, 27(3), 456-469.

Deschamps, P. (2018). Gender quotas in hiring committees: A boon or a bane for women? Sciences Po LIEPP Working Paper, 82.

Drucker-Godard, C., Fouque, T., Gollety, M., \& Le Flanchec, A. (2017). Enseignant-chercheur au féminin: La place des femmes dans les universités. Recherches en Sciences de Gestion, 118(1), 125-145.

Dubois, N. (1994). La norme d'internalité et le libéralisme. Presses Universitaires de Grenoble.

Ellemers, N., Van Den Heuvel, H., De Gilder, D., Maass, A., \& Bonvini, A. (2004). The underrepresentation of women in science: Differential commitmet or the queen bee syndrome? British Journal of Social Psychology, 43(3), 315-338.

Faniko, K., Burckhardt, T., Sarrasin, O., Lorenzi-Cioldi, F., Sorensen, S., Iacoviello, V., \& Mayo, E. (2017a). Quota women are threatening to men: Unveiling the (counter) stereotypization of beneficiaries of affirmative action policies. Swiss Journal of Psychology, 76(3), 107. 
Faniko, K., Chipeaux, M., \& Lorenzi-Cioldi, F. (2018). Le phénomène de la reine des abeilles: comment et pourquoi les femmes renforcent les inégalités de genre. In K. Faniko, D. Bourguignon, O. Sarracin, \& S. Guimond (Coords.), Psychologie de discrimination et des préjugés: De la théorie à la pratique (pp. 129-143). De Boeck Supérieur.

Faniko, K., Ellemers, N., \& Derks, B. (2016). Queen bees and alpha males: Are successful women more competitive than successful men? European Journal of Social Psychology, 46(7), 903-913.

Faniko, K., Ellemers, N., Derks, B., \& Lorenzi-Cioldi, F. (2017b). Nothing changes, really: Why women who break through the glass ceiling end up reinforcing it. Personality and Social Psychology Bulletin, 43(5), 638-651.

Gibson, D. E., \& Cordova, D. I. (1999). Women's and men's role models: The importance of exemplars. In A. J. Murrell, F. J. Crosby, \& R. J. Ely (Eds.), Mentoring dilemmas: Developmental relationships within multicultural organizations (pp. 121-141). Lawrence Erlbaum Associates Publishers.

Jacquemart, A., \& Sarfati, F. (2016). Genre et rapport subjectif au travail à l'université. In R. Rogers, \& P. Molinier (Dir.), Les femmes dans le monde académique: Perspectives comparatives (pp. 95-106). Presses Universitaires de Rennes.

Latour, E. (2008). Le plafond de verre universitaire: Pour en finir avec l'illusion méritocratique et l'autocensure. Mouvements, 55-56(3-4), 53-60.

Marry, C., \& Jonas, I. (2005). Chercheuses entre deux passions. Travail, Genre et Sociétés, 2, 69-88.

Marry, C., \& Pochic, S. (2017). The "glass ceiling" in France: Is the public sector more egalitarian than the private sector? Cadernos de Pesquisa, 47(163), 148-167.

Revillard, A. (2014). Les inégalités de genre dans l'enseignement supérieur et la recherche: Discussion autour du LIEPP Policy Brief, 14.

Rossiter, M. W. (1995). Women scientists in America: Before affirmative action, 1940-1972. Johns Hopkins University Press.

Schweitzer, S. (2009). Du vent dans le ciel de plomb? Laccès des femmes aux professions supérieures, XIXe-XXe siècles. Sociologie du Travail, 51(2), 183-198.

Texier-Picard, R. (2011). In Conférence Permanente des Chargé.e.s de Mission Egalité Diversité (CPED).

\section{Nota sobre autoria}

Este artigo foi elaborado em conjunto pelas autoras. Ambas idealizaram o projeto; coletaram e analisaram dados; dedicaram-se à elaboração e revisão do manuscrito. As atividades de pesquisa realizadas fizeram parte do plano de trabalho referente à bolsa de pesquisa do Coimbra Group Latin America Scholarship Programme, da qual a primeira autora se beneficiou.

\section{Disponibilidade de dados}

Os conteúdos subjacentes ao texto da pesquisa estão contidos no manuscrito.

\section{Como citar este artigo}

Grangeiro, R. da R., \& Esnard, C. (2021). O fenômeno abelha-rainha: Quais as particularidades na universidade? Cadernos de Pesquisa, 51, Artigo e07516. https://doi.org/10.1590/198053147516 